\title{
TLE3 represses colorectal cancer proliferation by inhibiting MAPK and AKT signaling pathways
}

Run-Wei Yang ${ }^{1,2,3 \dagger}$, Ying-Yue Zeng ${ }^{1,2,3 \dagger}$, Wen-Ting Wei ${ }^{1,2,3 \dagger}$, Yan-Mei Cui ${ }^{1,2,3}$, Hui-Ying Sun ${ }^{1,2,3}, y^{\prime}$ Xin-Xin Nian ${ }^{1,2,3}$, Yun-Teng Hu ${ }^{1,2,3}$, Yu-Ping Quan ${ }^{1,2,3}$, Sheng-Lu Jiang ${ }^{1,2,3}$, Meng Wang ${ }^{1,2,3}$, Ya i Zhao, Z, ${ }^{1,2,3}$, Jun-Feng Qiu, 1,2,3, Ming-Xuan Li ${ }^{1,2,3}$, Jia-Huan Zhang ${ }^{1,2,3}$, Mei-Rong He${ }^{4}$, Li Liang ${ }^{1,2,3}$, Yan- Óing ing and Wen-Ting Liao ${ }^{1,2,3,5^{*}}$

\section{Abstract}

Background: Transducin-like enhancer of Split3 (TLE3) serves as a transcripu pressor during cell differentiation and shows multiple roles in different kinds of cancers. Recently, $z$ together with many other genes involved in Wnt/ $\beta$-catenin pathway were detected hyper-meth, in colorectal cancer (CRC). However, the potential role and the underlying mechanism of TLE3 in CRC progression remain scarce.

Methods: Gene expression profiles were analyzed in The Can Genome Atlas (TCGA) microarray dataset of 41 normal colorectal intestine tissues and 465 CRC tissues. y stern ot and Real-time Quantitative PCR (RT-qPCR) were respectively performed to detect protein and mRNA vress on in 8 pairs of CRC tissue and matched adjacent normal mucosa. Immunohistochemistry (IHC) was onducted evaluate TLE3 protein expression in 105 paraffinembedded, archived human CRC tissues from natic who survival data were analyzed with Kaplan-Meier method. In vitro experiments including MTT/ ssay, co, vormation assay, and soft agar formation assay were used to investigate the effects of TLE3 on CRC ell wwth and proliferation. Additionally, subcutaneous tumorigenesis assay was performed in nude mice to eunfirm th. fffects of TLE3 in vivo. Furthermore, gene set enrichment analysis (GSEA) was run to explore $\mathrm{p}$ tential mechanism of TLE3 in CRC, and then we measured the distribution of CRC cell cycle phases and apoptosis v flow ytometry, as well as the impacts of TLE3 on MAPK and AKT signaling pathways by Western blot and RT-qP

Results: TLE3 was significantly av agulated in 465 CRC tissues compared with 41 normal tissues. Both protein and mRNA expressions TLE3 Rere down-regulated in CRC compared with matched adjacent normal mucosa. Lower expression of LE3 vas sic,nificantly associated with poorer survival of patients with CRC. Besides, knock down of TLE3 promo. 'Cnc cell growth and proliferation, while overexpression of TLE3 showed suppressive effects. Furthe ore, ove pression of TLE3 caused G1-S phase transition arrest, inhibition of MAPK and AKT pathways, and $d u_{1}$ egulation of p21Cip1/WAF1 and p27Kip1.

Conclusion: This sty dy indicated that TLE3 repressed CRC proliferation partly through inhibition of MAPK and AKT signar. o thw ays, suggesting the possibility of TLE3 as a biomarker for CRC prognosis.

ka. ords $\angle 3$, Proliferation, Prognosis, Colorectal cancer, p21Cip1/WAF1, p27Kip1

*Correspondence: dyq@fimmu.com; liaowt2002@gmail.com

${ }^{\dagger}$ Equal contributors

'Department of Pathology, Nanfang Hospital, Southern Medical University,

Guangzhou 510515, Guangdong, China

Full list of author information is available at the end of the article 


\section{Background}

Colorectal cancer (CRC) is one of the most commonly studied malignancies because of high morbidity and mortality [1]. CRC carcinogenesis is a multistep progress involving progressive genetic mutations, epigenetic adaptation, and immunology aberrances [2-4], which lead to the complexity of clinical treatment. Although continuous progresses were obtained in diagnostic and therapeutic methods, the prognosis and outcome of CRC patients are far away from satisfaction [5]. Recent studies intensively focus on personalized therapy that requires efficient biomarkers capable of assisting early diagnosis and treatment $[6,7]$. However, current biomarkers of CRC are unmet $[8,9]$.

Groucho (Gro)/TLE proteins belong to a large family of transcriptional corepressor that are extensively expressed in most metazoans. They show high conservation in structure and function of C-terminal tryptophan-aspartate (WD)-repeat domain and $\mathrm{N}$-terminal glutamine-rich $(\mathrm{Q})$ domain [10]. After direct interaction with DNA-bound transcriptional factors through WD-repeat domain, the Gro/TLE proteins form into polymer via $\mathrm{Q}$ domain with each other along the chromosome, and then recruit histone deacetylases to establish a transcriptionally silenced chromatin structure [10-12]. This complex exerts long-range repression on a variety of transcriptional factors including the members of Hes, Runx, Lcf/Lef, Pax, Six, and M families $[11,13]$. In this way, the Groucho/TL pro s participate in receptor tyrosine kinase (D, )/Ras/Ra mitogen-activated protein kinase (MAPK), Not Wnt, and Hedgehog signaling pathways $d$ aring proces,es of embryonic development, morphogene s and cell metabolism, as well as neoplastic conditions $\left[\begin{array}{ll}1 & 1 \\ 1 & -18\end{array}\right]$.

Transducin-like enhancer of - 1 lit 3 (ILE3) is one of the full-length members of him 1 an family [19]. Besides dynamic function in ifferentiation and cell metabolism [15, 20- T, T 52 en erty in tumoriger is. . vas initially found elevated in cervical and onic ne plasms [23, 24]. However, methylation scatus alyses of colorectal tumors showed aberrant methylation in the CpG island of TLE3 when compar w h d djacent normal mucosa [25]. Additionally terea pression of TLE2 and TLE3 were associated ith igh-gr de meningioma [26], and the alternatively $\mathrm{s}_{\mathrm{P}}$ ea lourorms of TLE3 were detected upregulated in pros $z$ tumor $[27,28]$. TLE3 was indifferent in leukemia, although other TLE proteins were observed coordinating with FOXG1 to promote B-lineage leukemia of positive E2A-HLF oncoprotein [29]. Interestingly, several studies proposed TLE3 as a potential marker of taxane responsiveness in the treatment of ovarian carcinoma and breast cancer [30, 31], but the most recent NCIC CTG MA.21 clinical trial repudiated TLE3 to be a valuable marker for taxane sensitivity in breast cancer treatment [32]. In short, these findings revealed the erratic role of TLE3 in human cancers. Further investigation of TLE3's pathological characteristics and clinical application in CRC will be of great significance.

Here, we sought to explore the expression pattern and potential role of TLE3 in the progression of CRC Our study showed that TLE3 expression was significan 'y downregulated in $\mathrm{CRC}$ tissue than matched adjacent no, mucosa. Lower expression level of TLE3 was associate poorer outcome of CRC patients. Furthern re, TLE? could arrested cell cycle progression and suppressea 11 pioliferation as well as tumor growth in $\mathrm{C} C$ partially hrough inhibition of MAPK and AKT pathw:

\section{Methods}

\section{Patients and specimers}

A total of 105 pathologic specimens were obtained from colon carcer atients between 2009 and 2014 at the Departmen. Jgy, Nanfang Hospital Southern Medical Universis Medical records of these patients provided mation of gender, age, and following essential factors tramy pathological characteristics, pathologic stage, T stag , Dukes stage, metastases of lymph node, and als metastasis. The 8 pairs of fresh biopsies collected from $\mathrm{RC}$ and their matched noncancerous mucosa tisyere obtained from the operation room of Nanfang Hospital. The fresh biopsies were stored in liquid nitrogen before usage. Approval was obtained from the Southern Medical University Institutional Board (Guangzhou, China) for the use of clinical materials for research purposes. All samples were collected and analyzed with the prior written, informed consent of the patients.

\section{Cell cultures}

The human CRC cell lines SW480, Ls174t, HCT15 and SW620 were purchased from American Type Culture Collection. SW620 were cultured in DMEM medium (Gibco) supplemented with $10 \%$ fetal bovine serum (FBS) (PAA Laboratories, Pasching, Austria). Ls174t, HCT15 and SW480 were cultured in RPMI 1640 medium (Gibco) with $10 \%$ FBS. Dissolved by DMSO, ERK inhibitor GDC0994 $(50 \mu \mathrm{M})$ and AKT inhibitor PF04691502 $(10 \mu \mathrm{M})$ (Selleck Chemicals, USA) were used to inhibit the activation of MAPK and AKT pathways, respectively. Cells were cultured at $37{ }^{\circ} \mathrm{C}$ with $5 \% \mathrm{CO}_{2}$.

\section{Plasmids}

The full-length TLE3 was amplified by PCR and cloned into pBabe (Addgene, Inc., Cambridge, MA, USA). The human short hairpin RNA (shRNA) sequences specifically targeting TLE3 (TLE3 shRNA\#1: 5'-CCACACG TTTGCAACCCAA-3'; TLE3 shRNA\#2: 5-CCTCCT GGTATCTGAACCA-3') were cloned into pSuperretroneo (Oligo-Engine, Seattle, WA, USA). 


\section{RNA isolation, reverse transcription (RT) and Real-time Quantitative PCR (RT-qPCR)}

Total RNA from cultured cells and CRC tissues was isolated using the mirVana miRNA Isolation Kit (Ambion) according to the manufacturer's instruction. The cDNA was then synthesized from total RNA using the Taqman miRNA reverse transcription kit (Applied Biosystems, Foster City, CA, USA). RT-qPCR was performed with the Applied Biosystems 7500 Sequence Detection system, using $\mathrm{iQ}^{\text {mix }}$ SYBR Green Supermix (BioRad Laboratories, Hercules, CA, USA). The data were normalized to the geometric mean of housekeeping gene GAPDH values and calculated as $2^{-\Delta \Delta C T}$ method. Sequences of the primers for RT-qPCR are summarized in Additional file 1: Table S1.

\section{Western blot}

We carried out western blot as previously described [33], using anti-TLE3 (Abcam, Cambridge, MA, USA), anti-FOXO3, anti-Akt, anti-GSK-3 $\beta$, anti-ERK, anti-p21, anti-p27, anti-p-FOXO3, anti-p-Akt, anti-p-GSK-3 $\beta$ and anti-p-ERK (Bioworld Technology, St. Louis Park, MN, USA) to detect the corresponding proteins. Anti- $\alpha$ Tubulin monoclonal antibody (Sigma, St. Louis, MO, USA) served as a loading control.

\section{Immunohistochemistry}

Immunohistochemistry (IHC) staining and scenting performed as previously described [33]. K; detecte, by anti-Ki-67 (Abcam, Cambridge, MA, US, represented the proliferation index.

\section{MTT assay}

Cells were incubated for $24 \mathrm{i}+37^{\circ} \mathrm{C}$ after the cells were trypsinized and plated on 90,1 plates $\left(1 \times 10^{3}\right)$. Then $20 \mu \mathrm{l}$ of $5 \mathrm{~g} / \mathrm{L} \mathrm{M}$ 3-(4, 5-dimethylthiazol-z-yl)2, 5-diphenyltetrazol. $\mathrm{b}$ mide, Sigma, St. Louis, MO, USA) was added and $\mathrm{m}$. into each well and incubated at $37{ }^{\circ} \mathrm{C}$. Aft $4 \mathrm{~h}$, the MTT-medium mixture was removed ana 15 ul dimethyl sulphoxide (DMSO, Sigma, St. Louis, Mo, USA) were added into the wells. The abs b...ce value was measured at $490 \mathrm{~nm}$ with a Mi plate utoreader (Bio-Rad, Hercules, CA, USA). $\checkmark$ hree dependent experiment was repeated. Data were $\mathrm{p}_{\star}$ inteu as the mean \pm SD.

\section{Colony formation assay}

Cells (200 cells/well) were trypsinized and plated on 6well plates, and then cultured in medium with $10 \%$ FBS for 2 weeks. The colonies were fixed with $4 \%$ paraformaldehyde for $5 \mathrm{~min}$ and stained with $1 \%$ crystal violet for $30 \mathrm{~s}$. Colonies of more than 50 cells were counted. The experiment was repeated for 3 times independently. Data were presented as the mean \pm SD.

\section{Soft agar assay}

$60 \mathrm{~mm}$ plates were covered with a layer of $0.66 \%$ agar in medium supplemented with $20 \%$ FBS. Cells $\left(1 \times 10^{4}\right)$ were seeded on the top of agar layer and cultured in RPMI 1640 supplemented with 10 \% FBS with $0.3 \%$ agarose. The cells were incubated with $5 \% \mathrm{CO}_{2}$ at $27{ }^{\circ} \mathrm{C}$. After 2 to 3 weeks, the number of cell col ny were counted under microscope and cell colonies we notographed in $100 \times$ view. Colonies of more than 50 \% $1 / 5$ were counted. The experiment was repo d for ? times independently, each cell line respectivcly. D were presented as the mean $\pm \mathrm{SD}$.

\section{Cell cycle analysis}

Cell cycle distribution as exa ed by measuring the cellular DNA conten $\mathrm{u}_{\mathrm{a}}$ flow sytometry. Cells at 80$90 \%$ confluence were inc ted for $36 \mathrm{~h}$ in the RPMI1640 medium CO ining $0.5 \%$ FBS, then released through cultu in RPMI-1640 medium with $10 \%$ FBS for $12, \times 10^{6}$ cells were collected and fixed with 70 ld et/anol. After treated with RNase A $(10 \mu \mathrm{g} / \mathrm{mL})$ for $00 \mathrm{~min}$ at $37{ }^{\circ} \mathrm{C}$, the cells were resuspended in $05 \mathrm{~mL}$ propidium iodide (PI) solution $(50 \mu \mathrm{g} /$ $\mathrm{m}_{\llcorner} 0.1 \%$ sodium citrate with $0.1 \% \mathrm{NP}-40$ ). Cell cycle tistri tion was analyzed by FACScan cytometry (Bectonkinson, San Jose, CA, USA).

\section{rumorigenesis assay}

Cells were trypsinized and then suspended with serumfree medium. $200 \mu \mathrm{l}$ cell suspension $\left(2 \times 10^{6}\right.$ cells $)$ was subcutaneously injected into 4-week-old Balb/Cathymic nude mice $(\mathrm{nu} / \mathrm{nu})$ obtained from the Animal Center of Southern Medical University, Guangzhou, Guangdong Province, China. All the animals were housed and maintained under specific pathogen-free conditions, and all experiments were approved by the Use Committee for Animal Care and performed in accordance with institutional guidelines. Tumor volumes were measured on the indicated days. Tumor size was measured by a slide caliper and tumor volume was determined by the formula $0.44 \times \mathrm{A} \times \mathrm{B}^{2}$ (A indicates tumor base diameter one direction and $B$ the corresponding perpendicular value). The tumors were fixed and $4 \mu \mathrm{m}$ sections were cut and stained with haematoxylin and eosin according to standard protocols. Sections were further under IHC staining using antibody against Ki-67.

\section{Statistical analysis}

All statistical analyses were carried out using SPSS version 19.0 for Windows (IBM, Armonk, NY, USA). The two-tailed Student's $t$-test was used to compare the intergroup. Survival data were analyzed with KaplanMeier method and were compared using the log-rank test. $p<0.05$ was considered statistically significant. 


\section{Results}

Down-regulation of TLE3 was associated with advanced progression and poor survival of human CRC

In order to identify deregulated genes involved in the progression of CRC, gene expression profiles were analyzed in The Cancer Genome Atlas (TCGA) microarray datasets. The analyses showed that TLE3 was significantly down-regulated in 465 CRC tissues compared to 41 normal tissues (Fig. 1a and b). Consistent with this finding, Western blot and real-time PCR analyses showed that TLE3 expression was significantly down-regulated in eight CRC tissues compared with adjacent normal intestine epithelial tissues (Fig. 1c and d). Furthermore, TLE3 protein expression was detected by immunohistochemistry (IHC) in 105 paraffin-embedded, archived human CRC tissues. TLE3 protein expression was quite abundant in adenoma as well as normal tissue, whereas it was markedly decreased in adenocarcinoma (Fig. 1e). Kaplan-Meier survival analysis showed that CRC patients with lower level of TLE3 protein expression had a poorer prognosis (Fig. 1f). These results sugge that TLE3 down-regulation is significantly associs ed with advanced progression of human CRC.

\section{Overexpression of TLE3 repressed the pro iration arid} tumorigenesis of human CRC cells

To investigate the potential role $C$ TLE3 in t,e progression of human CRC, stable CRC ell lines SW480 and Ls174t of TLE3 overexpressic ver wlished (Fig. 2a). In comparison with control c the proliferation of

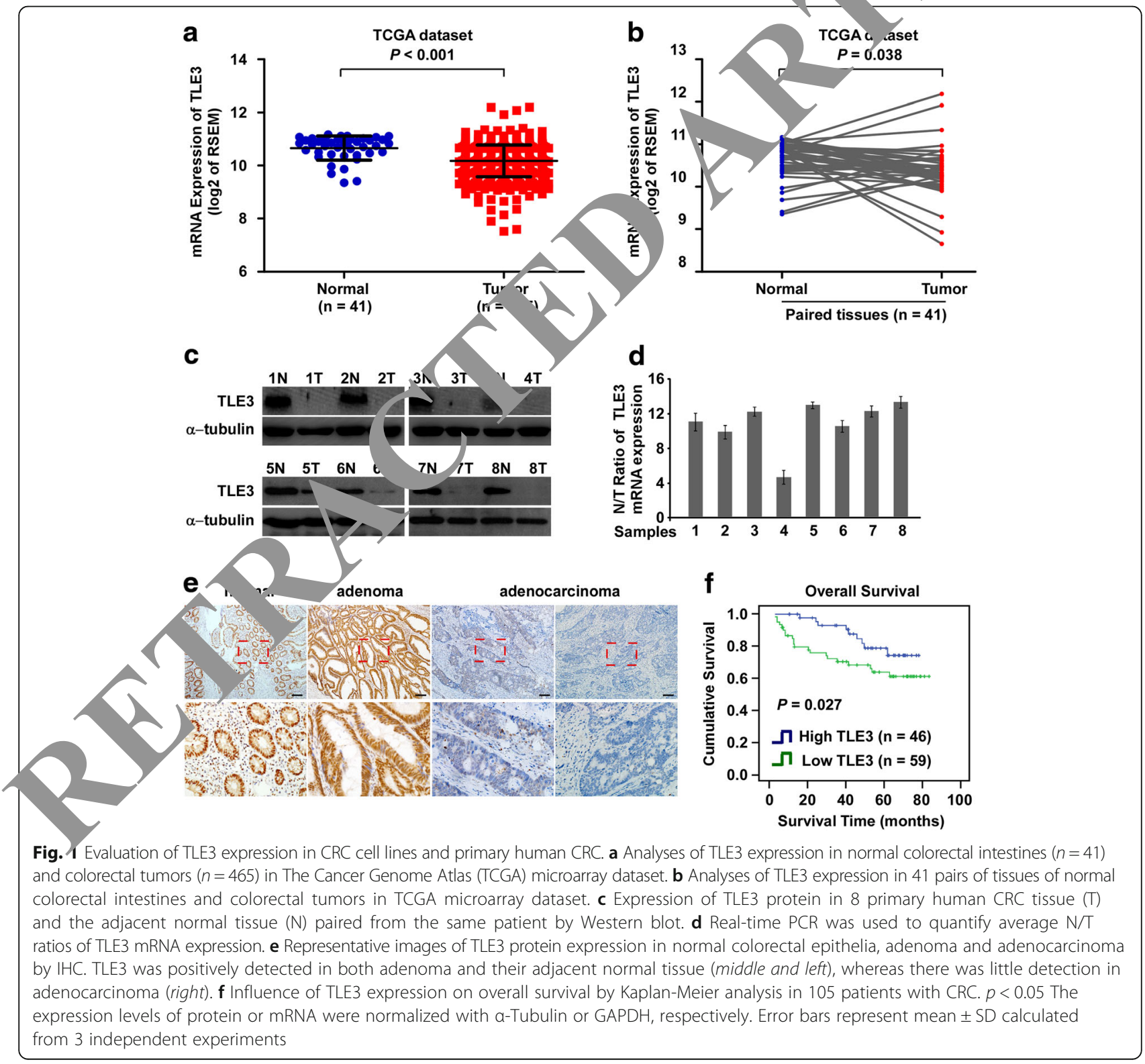



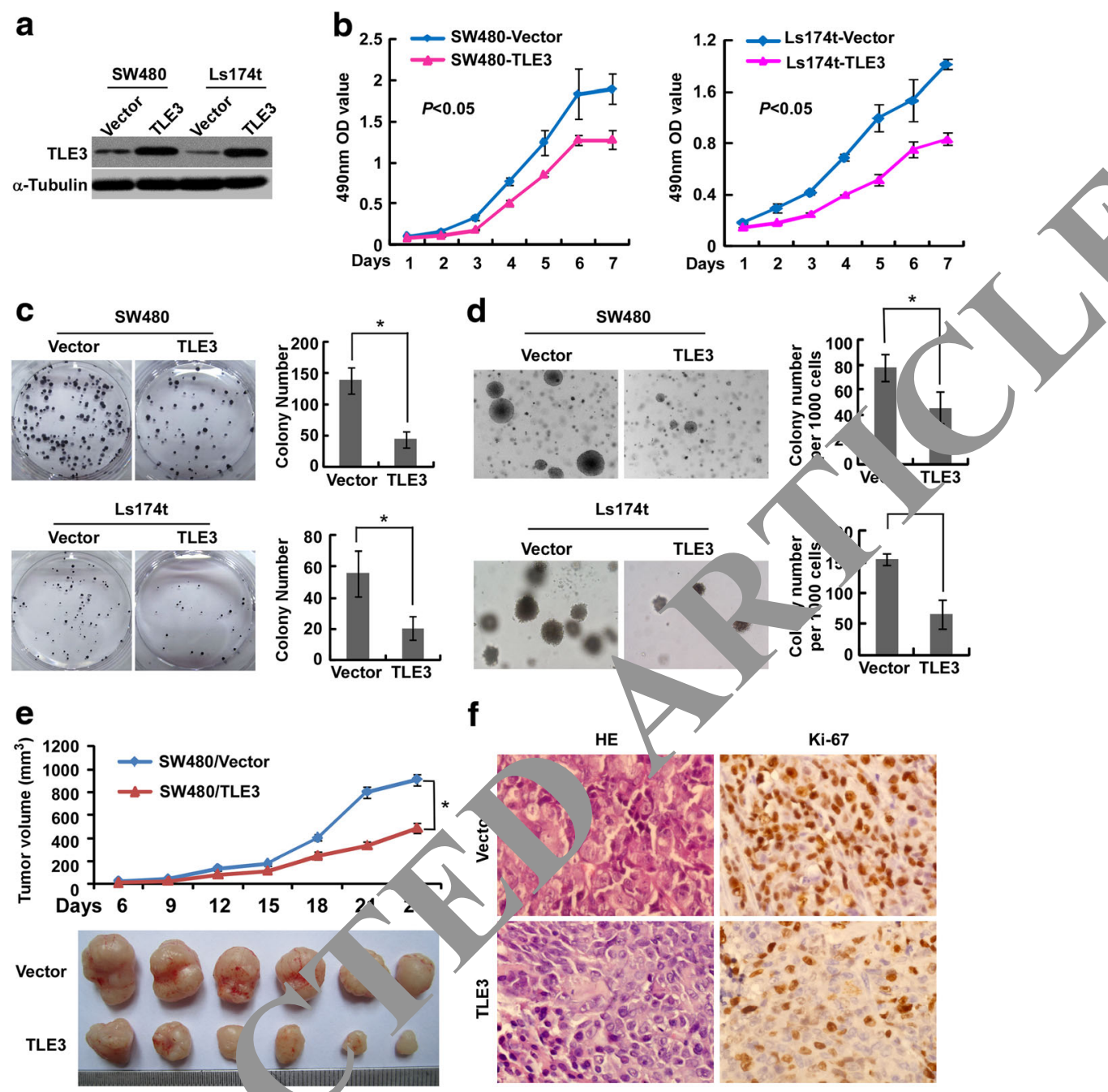

Fig. 2 Overexpression of TLE3 repres d the promicration and tumorigenesis of human CRC cells. a Overexpression of TLE3 in SW480 and LS174t cells. a-Tubulin was used as a loading on anerexpression of TLE3 repressed cell proliferation of SW480 and Ls174t cells by MTT assays. c Overexpression of TLE3 repressed cell o olife, ation of SW480 and Ls174t cells by colony formation assays. d Overexpression of TLE3 repressed anchorage-independent growt bility o SW480 and Ls174t cells as determined by soft agar assays. Colonies containing more than 50 cells were scored. e Tumorigenesis of b o measured on the ind cated Data points are the mean tumor volumes \pm SD. $p<0.05$. $\mathbf{f}$ The sections of tumor were under H\&E staining or subjected to IHC ning using antibody against Ki-67. Error bars represent the mean \pm SD of 3 independent experiments. ${ }^{*} p<0.05$

SW480 and Ls174t o, Als was inhibited by TLE3 overexpression dete mined by MTT and colony formation ass ( $\mathrm{Fi}_{\mathrm{s}} \mathrm{b}$ and $\left.\mathrm{c}\right)$. Anchorage-independent growth tivi was cxamined using soft agar formation assays, $w$. e cualts showed that TLE3 overexpression also repr ed the proliferation of SW480 and Ls174t cells in soft agar, as both the number and size of colonies were decreased in comparison with control cells (Fig. 2d). To confirm this effect in vivo, tumorigenesis assays by subcutaneous injection were performed in nude mice. The TLE3 overexpression group exhibited remarkably slower tumor growth and smaller tumor volume in comparison with the control group (Fig. 2e, $n=6$ ). In addition to the difference of tumor volume, much lower
Ki-67 index was found in tumors formed by TLE3 overexpression group than that in the control group, as detected by IHC analysis of Ki-67 (Fig. 2f).

\section{Knock-down of TLE3 promoted the proliferation and tumorigenesis of human CRC cells}

To further confirm the role of TLE3 in human CRC cells proliferation, endogenous expression of TLE3 in HCT15 and SW620 was knocked down by specific shRNAs (Fig. 3a). MTT and colony formation assays indicated that knock-down of TLE3 expression obviously promoted the cell growth of HCT15 and SW620 cells in comparison with control cells (Fig. 3b and c). Besides, the number and size of colonies in soft agar assays were 
a

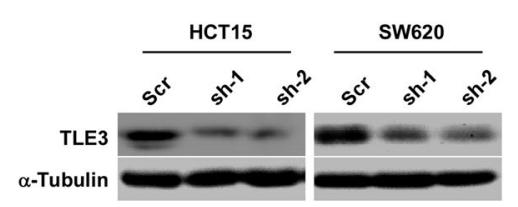

C
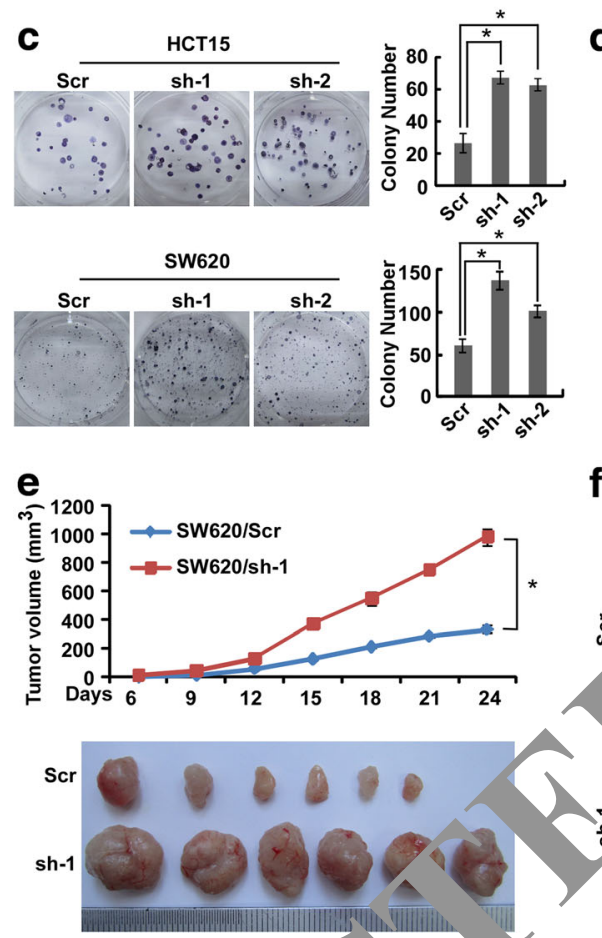

Fig. 3 Knock-down of TLE3 promoted the pro'eration and tul, iorigenesis of human CRC cells. a RNAi-silencing of TLE3 in shRNA-transduced stable HCT15 and SW620 cells. a-Tubulin was sed as a lgading control. b Knock-down of TLE3 promoted cell proliferation of HCT15 and SW620 cells by MTT assays. c Knock-down of TLE3 pr ted ce/ proliferation of HCT15 and SW620 cells by colony formation assays. d Knock-down of TLE3 promoted anchorage independent growt1_. of HCT15 and SW620 cells as determined by soft agar assays. Colonies containing more than 50 cells were scored. e Tumorigen av by subcutaneous injection of SW620/Scr and SW620/sh-1 cells in nude mice ( $n=6 /$ group). Tumor volumes were measured on the indicate $\mathbf{S}$ ays. ata points are the mean tumor volumes \pm SD. $\mathbf{f}$ The sections of tumor were under $\mathrm{H} \& \mathrm{E}$ staining or subjected to IHC staining usi antibody against Ki-67. Error bars represent the mean \pm SD of 3 independent experiments. ${ }^{*} p<0.05$

significantly ir sed in TLE3-silenced HCT15 and SW620 cells in con, rison with control cells (Fig. 3d). Furthermore, knockdowr of endogenous TLE3 expression in SW625 "s. d th noteworthy promotion of tumor growth and olum $n$ the tumorigenesis assays by subcutaneous iect, $n$ in nade mice, confirming the suppressive effect of 1. On $\subset \mathrm{RC}$ proliferation in vivo (Fig. 3e; $n=6$ ). In contrast tumors of TLE3 overexpression, Ki-67 index was found much higher in tumors of TLE3 knock-down in comparison with control cell-based tumor (Fig. 3f).

\section{TLE3 caused cell cycle G1-S phase transition arrest in human CRC cell}

To explore the possible mechanism by which TLE3 regulates the proliferation of human CRC cells, we analyzed TLE3 RNA expression levels based on TCGA COAD
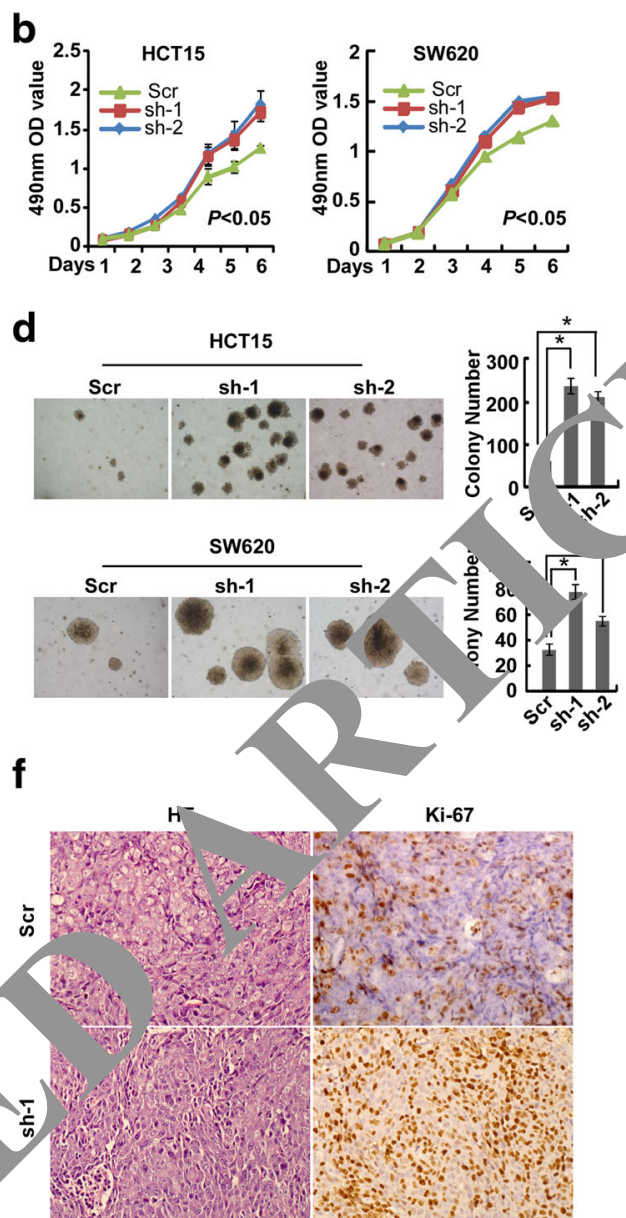

RNA Seq dataset and cycling gene signatures from the online Gene Set Database of the gene set enrichment analysis (GSEA) [34]. We observed that TLE3 expression was negatively correlated with genes related to cell cycle and G1-S transition (Additional file 2: Figure S1a and b). Furthermore, flow cytometry was performed to measure the distribution of cell cycle phases. Compared with control cells, the percentage of G1-phase cells increased and S-phase decreased significantly in the SW480 cells with TLE3 overexpressing (27.14 vs $41.55 \%, p<0.05$, and 49.47 vs $34.02 \%, p<0.05$, respectively) (Fig. $4 \mathrm{a}$ and Additional file 3: Figure S2a). Another cell line Ls174t of TLE3 overexpression showed the same results (29.38 vs $51.22 \%, p<0.05$ and 52.67 vs $41.38 \%, p<0.05$, respectively) (Fig. 4a and Additional file 3: Figure S2a). On the contrary, decrease in the percentage of G1-phase cells 


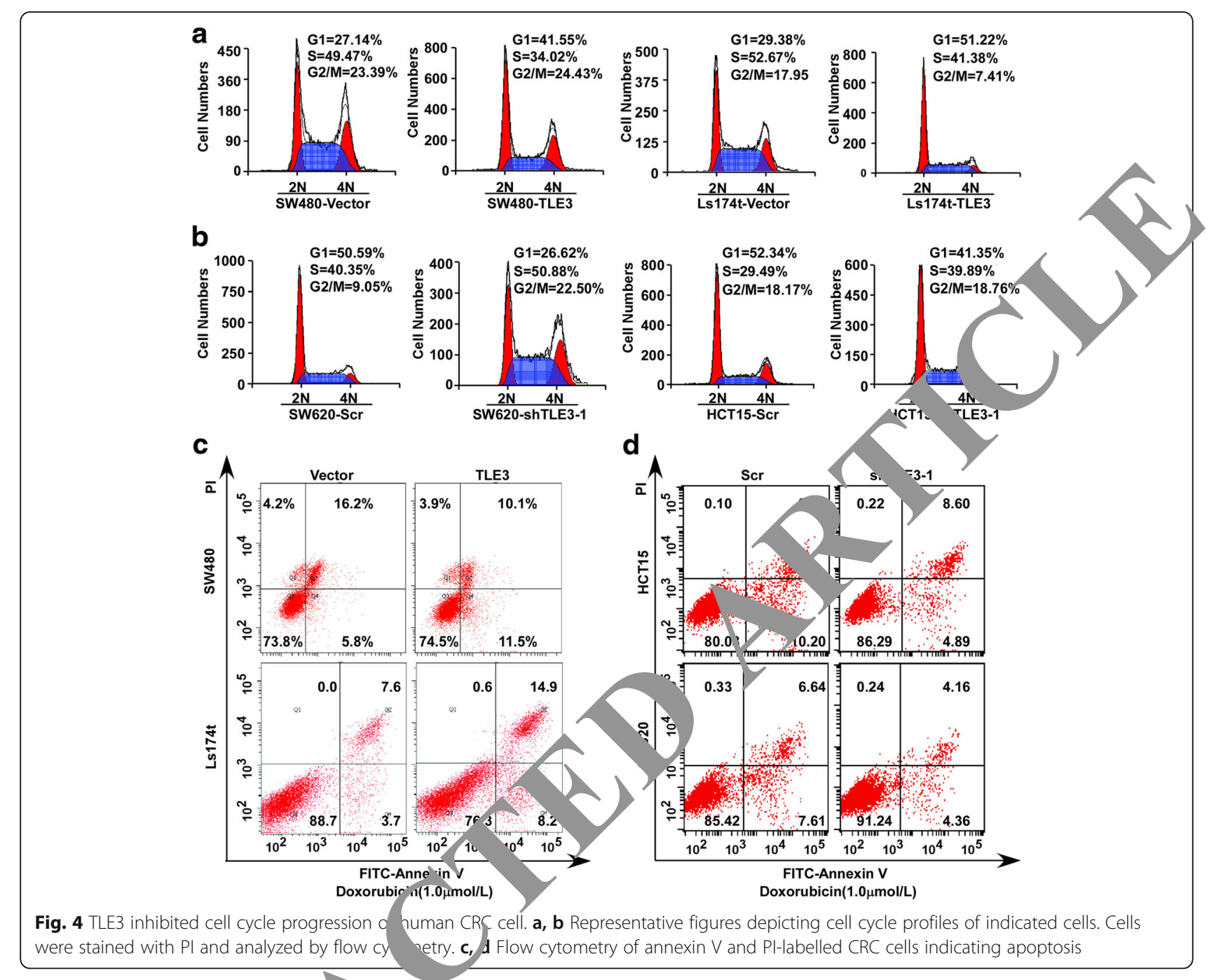

and increase in the percentage off $>$ se were observed after endogenous TLE3 HCT15 and SW620 cells was knocked down. Th ner nntaof of S-phase cells in HCT15 and SW/20 o of TLE3 knock-down were significantly $\mathrm{m}$, than the, in HCT15 and SW620 cells of control group ( -35 vs $50.88 \%, p<0.05$ and 29.49 vs $39.88 \% p<0.05$, re,pectively) (Fig. $4 \mathrm{~b}$ and Additional file 3. $5 \mathrm{~b}$ ). Moreover, TLE3 overexpressing sigr.ricant, incleased the percentage of apoptotic cells S 480 and Ls174t cells, whereas knockdown of 1. III W620 and HCT15 cells decreased the number of a totic cells (Fig. 4c and d, Additional file 3: Figure S2c and d). Taken together, these results demonstrate that TLE3 inhibits cell cycle progression and promotes cell death in CRC cells.

\section{TLE3 suppressed CRC partly through inhibition of MAPK and AKT signaling pathways}

The GSEA analysis based on TCGA COAD RNA expression dataset also revealed that TLE3 level was negatively correlated with AKT activity (Additional file 4: Figure S3), indicating that TLE3 might inhibit the activation of AKT signaling pathway. Moreover, Western blot showed that the levels of phosphorylated FOXO3, GSK, ERK and AKT were decreased in SW480 and Ls174t cells with TLE3 overexpressing, whereas increased in HCT15 and SW620 cells with TLE3 knocking down in comparison with control cells (Fig. 5a). Since TLE3 significantly inhibited the G1-S phase transition as shown above, we then detected the cyclindependent kinases inhibitor proteins p21Cip1/WAF1 (p21) and p27Kip1 (p27) that are responsible for this transition $[35,36]$. Results showed that $\mathrm{p} 21$ and $\mathrm{p} 27$ were upregulated in SW480 and Ls174t cells with TLE3 overexpressing (Fig. 5a), whereas they were down-regulated in HCT15 and SW620 cells with TLE3 knocking down (Fig. 5a). Additionally, transcriptional levels of p21 and p27 were also regulated by TLE3 (Additional file 5: Figure S4 a, b, c and d).

To investigate whether the alterations of p21 and p27 were caused by activation of the MAPK or AKT pathways, SW620 cells with TLE3 knocking down were 


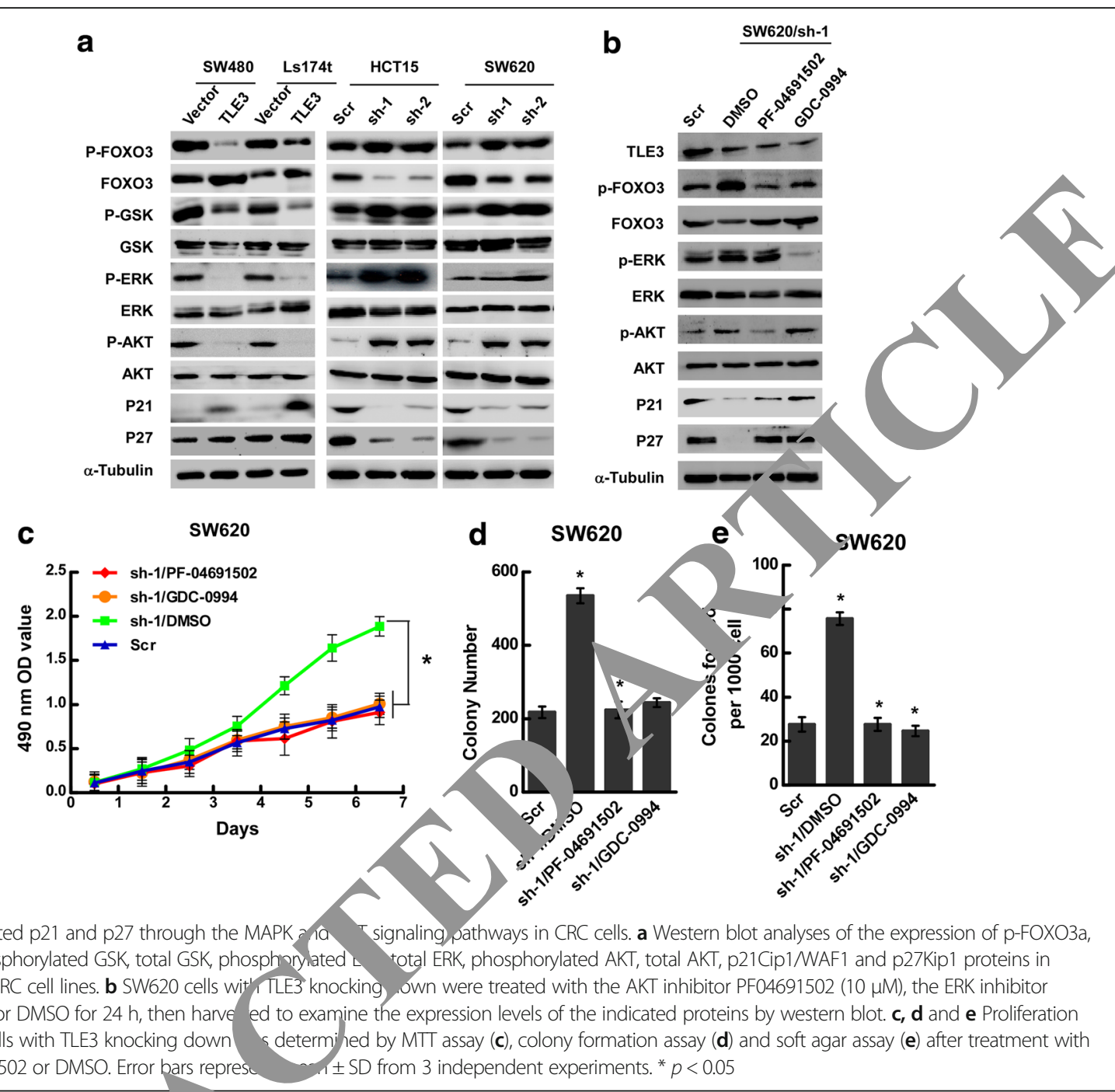

treated with an ERK $\mathrm{j}$ tor (GDC0994)[37] or AKT inhibitor (PF046915 $\ulcorner 38$ Fioule $5 \mathrm{~b}$ showed that the expression levels or pho horylated ERK and AKT were significantly $\mathrm{r}$ e ed by JC0994 and PF04691502 in SW620 cells, iespe vely. Notably, the expression of p21 and p27 were rescu, d by treatment with the ERK or $\mathrm{AKT}$ in $\mathrm{it}, \mathrm{rs}$ ompared to control cells treated with $\mathrm{DN}$ MCO $\left(\mathrm{Fi}_{\varepsilon}-\mathrm{b}\right)$.

To urther confirm that TLE3 represses proliferation b) InIving the MAPK and AKT pathways, the growth abili of SW620 cells with TLE3 knocking down after treatment with GDC0994 or PF04691502 were examined. MTT assay, colony formation assay and soft agar assay showed that the growth of SW620 cells were significantly compromised by treatment with the ERK or AKT inhibitors compared to control cells treated with DMSO (Fig. 5c, d and e).

Collectively, these results indicate that TLE3 represses the proliferation of CRC cells partly through inhibition of MAPK and AKT signaling pathways and activation of p21 and p27.

\section{Discussion}

Although TLE3 gene was detected hyper-methylated in CRC [25], our study firstly reported the down-regulation of TLE3 on both protein and mRNA levels. Results revealed that low expression of TLE3 in CRC was significantly correlated with advanced progression and poor survival of patients. In addition, TLE3 expression was observed negatively associated with CRC growth both in vitro and in vivo. However, whether TLE3 could be used as a valuable biomarker for CRC prognosis needs further investigation.

The TLE family show structural redundancy [19] but play multiple roles during tumorigenesis. For instance, TLE1 coordinated with Qin to promote cell growth and agar colony formation in chicken embryo fibroblasts [39]. TLE2 was discovered to bind with replication and 
transcription activator (RTA) and thus inhibited RTAmediated replication and transactivation that was implicated with Kaposi's sarcoma-associated herpesvirus [40]. TLE1 and TLE4 served as a tumor suppressor gene in acute myeloid leukemia [41, 42], while it turned to be oncogenes in lung cancer and colorectal cancer, respectively [43-45]. Another member of TLE family, the TLE3 also performs various roles in cancers, especially in clinical treatments containing taxane therapy as mentioned above. On the one hand, TLE3 was found elevated in cervical neoplasms [23, 24], high-grade meningiomas [26], and prostate tumor [27, 28]. On the other hand, high expression of TLE3 was associated favorable responses to taxane-containing therapies in ovarian carcinoma [31] but not in breast cancer [32] and angiosarcoma [46]. Noteworthy, Zagouras P et al. reported that TLE family proteins were up-regulated in colonic adenocarcinoma as detected by panTLE antibody that recognized the entire TLE family [23], whereas our study showed that TLE3 was down-regulated in CRC. In addition, previous studies have showed hyper-methylation of TLE3 [25] and overexpression of TLE4 in CRC [43]. Taken together, we inferred that it was TLE4, TLE1 and TLE2 but not TLE3 that were overexpressed in colonic adenocarcinoma. The multiple properties of TLE family were explained by context-dependent characteristics $[1]$, but the underlying mechanism remains largely ur on ? and emerge great potential in cancer research.

As an element of Notch signaling that lates ce, fate determination, TLE3 participates in cell a ventiation under physiological circumstan e [21, 47-5, ]. As for CRC cancer, we observed that T E3 could cause the G1-S phase transition arrest in a certal vtent and repress the growth and proliferation of CRC. Born p21 and p27 have been identified as mediators on amor suppression through G1 or G2 arre volving binding to CyclinA/ cyclin-dependent $\mathrm{kj}$ - e (DK) L, CyclinE/CDK2, and CyclinD/CDK4/6 Com res $[35,36,52]$. Loss of p21 and p27 coula nhance cumorigenesis [53]. Further studies have reve, that Ras/MAPK and PI3K/AKT signaling were closel/associated with $\mathrm{p} 21$ and p27. On the one $n . R$ s s/MAPK and PI3K/AKT signaling play viton oles $\mathrm{p}$ /oliferation partly via the regulation of vclir $) 1$ an $\mathrm{CDK}$ inhibitors including p21 and p27 [3. 50]. The ubiquitylation-dependent proteasomal degi ation of p21 and p27 is mediated by Ras/MAPK and PI3K/AKT signaling [57]. On the other hand, p27Kip1 promoter could be activated by the FOXO family (FOXO4, FOXO3a, and FOXO1), whose activity was modulated by Ras/MAPK and PI3K/AKT pathways [58-60]. Moreover, Gro is a junction of Ras-associated network of multiple signaling cascades, which could attenuate the Gro-dependent repression [17, 61]. Here, we showed that p-ERK, p-GSK and p-AKT were down- regulated by TLE3, indicating the suppressor role of TLE3 in MAPK and PI3K/AKT pathways. Correspondingly, p21 and p27 protein expression were upregulated by TLE3. In addition, TLE3 enhanced the transcription of p21 and p27, which could be explained by the contribution of FOXO3a.

\section{Conclusions}

Collectively, our study uncovered another novel a ct of TLE3 in the progression of CRC. Lom expres rion of TLE3 was closely associated with nore ac noed CRC progression and poorer outcome of patients with CRC, while overexpression of TLE3/sup essed CRC proliferation both in vitro and in vivo Jurtinn.nore, TLE3 could cause G1-S phase trar sition a st by increasing the expression of $\mathrm{p}^{21}$ an $\mathrm{p}_{2}$ the underlying mechanism of which was TLE3-mediate inhibition of MAPK and AKT signaling pat ways. These findings indicate the potential of Tiomarker for CRC prognosis. However the deta 1 mechanism of TLE3 in CRC progression $\mathrm{r}$ further investigations.

\section{Additional files}

Addi ,nal file 1: Table S1. Primer Sequences used for RT-qPCR (5' to 3') Oc. $13 \mathrm{~kb}$ )

A dditional file 2: Figure S1. Gene set enrichment analyses of TLE3 based on TCGA COAD RNA Seq dataset. a TLE3 expression negatively was correlated with genes related to cell cycle. $\mathbf{b}$ TLE3 expression was negatively correlated with genes related to G1-S transition. (PNG $116 \mathrm{~kb}$ )

Additional file 3: Figure S2. Statistical analyses of flow cytometry indicated that overexpression of TLE3 caused the arrest of G1-S phase transition (a) and increased apoptosis of CRC cells (c), while knockdown of TLE3 promoted the G1-S phase transition (c) and inhibited apoptosis of CRC cells (d). Error bars represent mean \pm SD from 3 independent experiments. ${ }^{*} p<0.05$. (PNG $202 \mathrm{~kb}$ )

Additional file 4: Figure S3. Gene set enrichment analysis of TLE3 based on TCGA COAD RNA Seq dataset showed that TLE3 expression was negatively correlated with AKT activity. (PNG 61 kb)

Additional file 5: Figure S4. RT-qPCR analyses of relative mRNA expression of p21Cip1/WAF1 and p27Kip1 in indicated CRC cell lines. Error bars represent mean \pm SD from 3 independent experiments. * $p<0.05$. (PNG $162 \mathrm{~kb}$ )

\section{Abbreviations}

CDK: Cyclin-dependent kinase; CRC: Colorectal cancer; Gro: Groucho; GSEA: Gene set enrichment analysis; HLF: Hepatic leukemia factor; IHC: Immunohistochemistry; MAPK: Mitogen-activated protein kinase; MTT: 3-(4, 5-dimethylthiazol-z-yl)-2, 5-diphenyltetrazolium bromide; p21: p21Cip1/WAF1; p27: p27Kip1; Q: Glutamine-rich; RT: Reverse transcription; RTA: Replication and transcription activator; RTK: Receptor tyrosine kinase; RT-qPCR: Real time quantitative polymerase chain reaction; shRNA: Short hairpin RNA; TCGA: The Cancer Genome Atlas; TLE: Transducinlike enhancer of Split; WD: Tryptophan-aspartate

\section{Acknowledgements}

Not applicable.

\section{Funding}

This work was supported by the National Basic Research Program of China (973 program, 2015CB554002), Project of the National Natural Science 
Foundation of China supported by NSFC-Guangdong Joint Fund (U1201226), the National Natural Science Foundation of China $(81472313,81172055$, and $81472710,81402277)$, Guangdong Provincial Natural Science Foundation of China (S2012010009643, 2014A030313283), the Science and Technology Innovation Foundation of Guangdong Higher Education (CXZD1016) and the Key Program of the National Natural Science Foundation of Guangdong (2010B031500012), Guangzhou Science \& Technology Plan Project (201300000056)

\section{Availability of data and supporting materials}

The microarray data were downloaded from the The Cancer Genome Atlas (TCGA) database (http://cancergenome.nih.gov/). Microarray data extracts were performed on MeV4.6 (http://www.tm4.org/). GSEA was performed using GSEA 2.0.9 (http://www.broadinstitute.org/gsea/).

\section{Authors' contributions}

WTL and YQD designed the experiments; RWY, YYZ, WTW, YMC, HYS, YLC, XXN and YTH conducted experiments; LL, MRH, YPQ, SLJ, MW, YLZ, JFQ, MXL and JHZ provided research materials and methods; RWY, YYZ and WTW analyzed data; and WTL and RWY wrote the manuscript. All authors read and approved the final manuscript.

\section{Competing interests}

The authors of this manuscript have no conflict of interest.

\section{Consent for publication}

All tissue samples were collected and analyzed with the prior written, informed consent of the patients.

\section{Ethics approval and consent to participate}

Ethics approval was obtained from the Southern Medical University Institutional Board (Guangzhou, China) for the use of clinical materials for research purposes.

\section{Author details}

'Department of Pathology, Nanfang Hospital, Southern Medical 1 Guangzhou 510515, Guangdong, China. ${ }^{2}$ Department of Path ogy, Scho of Basic Medical Sciences, Southern Medical University, Gurn Guangdong, China. ${ }^{3}$ Guangdong Provincial Key Laboratory of Mo lar Tumor Pathology, Guangzhou, Guangdong, China. ${ }^{4}$ suangdong Pro ćral Key Laboratory of Gastroenterology, Department c Gastroenterology, Nanfang Hospital, Southern Medical University, Gu gzhou, Gylangdong, China. ${ }^{5}$ Department of Pathology, Nanfang Hospita + Scho of of Basic Medical Sciences, Southern Medical Unive sitv, Guangamur s10515, Guangdong, China.

Received: 25 May 2016 Accept Septe nber 2016 Published online: $27 \mathrm{Sep}^{+}$nber 016

\section{References}

1. Torre LA, Bray F V RL, Ferlay, Lortet-Tieulent J, Jemal A. Global cancer statistics, 201 _CA C. v J Clin. 2015;65(2):87-108.

2. West NR Nuaig S, Fin Ki F, Powrie F. Emerging cytokine networks in colr ectal cancer. Nat hev Immunol. 2015;15(10):615-29.

3. Migilo spelisni R, Coppede F. Genetics, cytogenetics, and enigenet, fols, rectal cancer. J Biomed Biotechnol. 2011;2011:792362. Zhou MicroRNAs in colorectal carcinoma-from pathogenesis to the I Fxp Clin Cancer Res. 2016;35:43.

5. renner-1, Kloor M, Pox CP. Colorectal cancer. Lancet. 2014;383(9927): -502 .

6. Jac adish N, Parashar D, Gupta N, Agarwal S, Purohit S, Kumar V, Sharma A Fatima R, Topno AP, Shaha C, et al. A-kinase anchor protein 4 (AKAP4) a promising therapeutic target of colorectal cancer. J Exp Clin Cancer Res. 2015;34:142.

7. Wang J, Cui F, Wang $X$, Xue Y, Chen J, Yu Y, Lu H, Zhang M, Tang H, Peng Z. Elevated kinesin family member $26 B$ is a prognostic biomarker and a potential therapeutic target for colorectal cancer. J Exp Clin Cancer Res. 2015:34:13.

8. Palma S, Zwenger AO, Croce MV, Abba MC, Lacunza E: From Molecular Biology to Clinical Trials: Toward Personalized Colorectal Cancer Therapy. Clin Colorectal Cancer. 2016;15(2):104-15.
9. Thomaidis T, Maderer A, Formentini A, Bauer S, Trautmann M, Schwarz M, Neumann W, Kittner JM, Schad A, Link KH, et al. Proteins of the VEGFR and EGFR pathway as predictive markers for adjuvant treatment in patients with stage II/II colorectal cancer: results of the FOGT-4 trial. J Exp Clin Cancer Res. 2014;33:83.

10. Chen G, Courey AJ. Groucho/TLE family proteins and transcriptional repression. Gene. 2000;249(1-2):1-16.

11. Jennings $\mathrm{BH}$, Ish-Horowicz D. The Groucho/TLE/Grg family of tran crmptional co-repressors. Genome Biol. 2008;9(1):205.

12. Chen G, Fernandez J, Mische S, Courey AJ. A functional interact the histone deacetylase Rpd3 and the corepressor groucho in Dro, hila development. Genes Dev. 1999;13(17):2218-30.

13. Turki-Judeh W, Courey AJ. Groucho: a corepressor development. Curr Top Dev Biol. 2012;98:65-96

14. Villanueva CJ, Vergnes L, Wang J, Drew BG, '

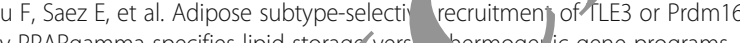
Cell Metab. 2013;17(3):423-35.

15. Villanueva CJ, Waki H, Godio C, wivsen hou WL, Vargas L, Wroblewski K, Schmedt C, Chao LC, Boyad R, et al. TL. a dual-function transcriptional coregulate of genesis. Lell Metab. 2011;13(4):413-27.

16. Laing AF, Lowell S, Brickman J/h ro/TLE enables embryonic stem cell differentiation by sung plurip rent gene expression. Dev Biol. 2015;397(1):56

17. Cinnamon E, Par 4 -dependent regulation of Groucho/TLEmediated repression.

18. Buscarle Stifani S. 1) C'Marx' of Groucho on development and disease. Trends C(IID) $\quad 7,17(7): 353-61$.

19. Stifani S, B a amuerer CM, Redhead NJ, Hill RE, Artavanis-Tsakonas S. Human homologs $\mathrm{f}$ a Drosophila Enhancer of split gene product define a novel nily of nuclear proteins. Nat Genet. 1992;2(4):343.

20. ga FJ, Serrano M, Rodriguez-Cuenca S, Moreno-Navarrete JM, GomezSe tno M, Sabater M, Rodriguez-Hermosa Jl, Xifra G, Ricart W, Peral B, et al. ransducin-like enhancer of split 3 (TLE3) in adipose tissue is increased in situations characterized by decreased PPARgamma gene expression. J Mol Med (Berl). 2015;93(1):83-92.

21. Kokabu S, Nguyen T, Ohte S, Sato T, Katagiri T, Yoda T, Rosen V. TLE3, transducing-like enhancer of split 3, suppresses osteoblast differentiation of bone marrow stromal cells. Biochem Biophys Res Commun. 2013;438(1): 205-10.

22. Cloonan N, Forrest AR, Kolle G, Gardiner BB, Faulkner GJ, Brown MK, Taylor DF, Steptoe AL, Wani S, Bethel G, et al. Stem cell transcriptome profiling via massive-scale mRNA sequencing. Nat Methods. 2008;5(7):613-9.

23. Zagouras P, Stifani S, Blaumueller CM, Carcangiu ML, Artavanis-Tsakonas S. Alterations in Notch signaling in neoplastic lesions of the human cervix. Proc Natl Acad Sci U S A. 1995;92(14):6414-8.

24. Liu Y, Dehni G, Purcell KJ, Sokolow J, Carcangiu ML, Artavanis-Tsakonas S, Stifani S. Epithelial expression and chromosomal location of human TLE genes: implications for notch signaling and neoplasia. Genomics. 1996;31(1):58-64.

25. Farkas SA, Vymetalkova V, Vodickova L, Vodicka P, Nilsson TK. DNA methylation changes in genes frequently mutated in sporadic colorectal cancer and in the DNA repair and Wnt/beta-catenin signaling pathway genes. Epigenomics. 2014;6(2):179-91.

26. Cuevas IC, Slocum AL, Jun P, Costello JF, Bollen AW, Riggins GJ, McDermott MW, Lal A. Meningioma transcript profiles reveal deregulated Notch signaling pathway. Cancer Res. 2005;65(12):5070-5.

27. Nakaya HI, Beckedorff FC, Baldini ML, Fachel AA, Reis EM, VerjovskiAlmeida S. Splice variants of TLE family genes and up-regulation of a TLE3 isoform in prostate tumors. Biochem Biophys Res Commun. 2007;364(4):918-23.

28. Reis EM, Nakaya HI, Louro R, Canavez FC, Flatschart AV, Almeida GT, Egidio CM, Paquola AC, Machado AA, Festa F, et al. Antisense intronic non-coding RNA levels correlate to the degree of tumor differentiation in prostate cancer. Oncogene. 2004;23(39):6684-92.

29. Dang J, Inukai T, Kurosawa H, Goi K, Inaba T, Lenny NT, Downing JR, Stifani S, Look AT. The E2A-HLF oncoprotein activates Groucho-related genes and suppresses Runx1. Mol Cell Biol. 2001;21(17):5935-45.

30. Kulkarni SA, Hicks DG, Watroba NL, Murekeyisoni C, Hwang H, Khoury T, Beck RA, Ring BZ, Estopinal NC, Schreeder MT, et al. TLE3 as a candidate biomarker of response to taxane therapy. Breast Cancer Res. 2009;11(2):R17. 
31. Samimi G, Ring BZ, Ross DT, Seitz RS, Sutherland RL, O'Brien PM, Hacker NF, Huh WK. TLE3 expression is associated with sensitivity to taxane treatment in ovarian carcinoma. Cancer Epidemiol Biomarkers Prev. 2012;21(2):273-9.

32. Bartlett JM, Nielsen TO, Gao D, Gelmon KA, Quintayo MA, Starczynski J, Han $L$, Burnell MJ, Levine MN, Chen BE, et al. TLE3 is not a predictive biomarker for taxane sensitivity in the NCIC CTG MA.21 clinical trial. Br J Cancer. 2015;113(5):722-8.

33. Liao WT, Wang X, Xu LH, Kong QL, Yu CP, Li MZ, Shi L, Zeng MS, Song LB. Centromere protein $\mathrm{H}$ is a novel prognostic marker for human nonsmall cell lung cancer progression and overall patient survival. Cancer. 2009;115(7):1507-17.

34. Subramanian A, Tamayo P, Mootha VK, Mukherjee S, Ebert BL, Gillette MA, Paulovich A, Pomeroy SL, Golub TR, Lander ES, et al. Gene set enrichment analysis: a knowledge-based approach for interpreting genome-wide expression profiles. Proc Natl Acad Sci U S A. 2005;102(43):15545-50.

35. Toyoshima H, Hunter T. p27, a novel inhibitor of G1 cyclin-Cdk protein kinase activity, is related to p21. Cell. 1994;78(1):67-74.

36. Hitomi M, Shu J, Agarwal M, Agarwal A, Stacey DW. p21Waf1 inhibits the activity of cyclin dependent kinase 2 by preventing its activating phosphorylation. Oncogene. 1998;17(8):959-69.

37. Mateu A, De Dios I, Manso MA, Ramudo L. Unsaturated but not saturated fatty acids induce transcriptional regulation of CCL2 in pancreatic acini. A potential role in acute pancreatitis. Biochim Biophys Acta. 2015;1852(12):2671-7.

38. Yuan J, Mehta PP, Yin MJ, Sun S, Zou A, Chen J, Rafidi K, Feng Z, Nickel J, Engebretsen J, et al. PF-04691502, a potent and selective oral inhibitor of PI3K and mTOR kinases with antitumor activity. Mol Cancer Ther. 2011; 10(11):2189-99.

39. Sonderegger CK, Vogt PK. Binding of the corepressor TLE1 to Qin enhances Qin-mediated transformation of chicken embryo fibroblasts. Oncogene. 2003;22(12):1749-57.

40. He Z, Liu Y, Liang D, Wang Z, Robertson ES, Lan K. Cellular corepressor TLE2 inhibits replication-and-transcription- activator-mediated transactivation and lytic reactivation of Kaposi's sarcoma-associated herpesvirus. J Virol. 2010; 84(4):2047-62.

41. Dayyani F, Wang J, Yeh JR, Ahn EY, Tobey E, Zhang DE, Bernstein ID, Peterson RT, Sweetser DA. Loss of TLE1 and TLE4 from the del(9q) commonly deleted region in AML cooperates with AML1-ETO to af myeloid cell proliferation and survival. Blood. 2008;111(8):433, -47 .

42. Schoch C, Haase D, Haferlach T, Gudat H, Buchner T, Freu ic Vink H, Lengfelder $\mathrm{E}$, Wandt $\mathrm{H}$, Sauerland MC, et al. Fifty-one pa ents acute myeloid leukemia and translocation $\mathrm{t}(8 ; 21)(\mathrm{q} 22 ; \mathrm{q} 27)$ \% arradditionar ction in $9 q$ is an adverse prognostic factor. Leukemia. 996;10(8):1288-95.

43. Wang SY, Gao K, Deng DL, Cai JJ, Xiao ZY, He L Jiao HL, YelYP, Yang RW, $\mathrm{Li}$ TT, et al. TLE4 promotes colorectal cancer pro cion thr ugh activation of JNK/C-Jun signaling pathway. Oncotarget. 2016,

44. Yao X, Ireland SK, Pham T, Temple B, Ch a MH, Biliran H. TLE1 promotes EMT in A549 lung cancer cells throay. appression of E-cadherin. Biochem Biophys Res Comm 14;455 (-4):277-84.

45. Allen T, van Tuyl M, lyenc P, Jo y S, Post M, Tsao MS, Lobe CG. Grg1 acts as a lung-specific oncoger no mouse model. Cancer Res. 2006;66(3):1294-30

46. Shon W, Jenkins Ross DT, Se RS, Beck RA, Ring BZ, Okuno SH, Gibson $\mathrm{LE}$, Folpe AL., ngios ma: a study of 98 cases with immunohistochemical evaluation f TLE3, a re tly described marker of potential taxane respon .iveress. J Cutan Pjathol. 2011;38(12):961-6.

47. Metze, DE $\because$ C, Ziaie AS, Naji A, Zaret KS. Grg3/TLE3 and Grg1/TLE1 induce i horm onal pancreatic beta-cells while repressing alpha-cell in tions. D. 20s. 2014;63(5):1804-16.

Ko hus. Sato T, Ohte S, Enoki Y, Okubo M, Hayashi N, Nojima J, S, Fukushima Y, Sakata Y, et al. Expression of TLE3 by bone row stromal cells is regulated by canonical Wnt signaling. FEBS Lett. 20 4;588(4):614-9.

49. Gasperowicz M, Surmann-Schmitt C, Hamada Y, Otto F, Cross JC. The transcriptional co-repressor TLE3 regulates development of trophoblast giant cells lining maternal blood spaces in the mouse placenta. Dev Biol. 2013;382(1):1-14.

50. Carvalho LR, Brinkmeier ML, Castinetti F, Ellsworth BS, Camper SA. Corepressors TLE1 and TLE3 interact with HESX1 and PROP1. Mol Endocrinol. 2010;24(4):754-65.

51. Nakayama H, Liu Y, Stifani S, Cross JC. Developmental restriction of Mash-2 expression in trophoblast correlates with potential activation of the notch-2 pathway. Dev Genet. 1997;21(1):21-30.
52. Kwon TK, Nagel JE, Buchholz MA, Nordin AA. Characterization of the murine cyclin-dependent kinase inhibitor gene p27Kip1. Gene. 1996;180(1-2):113-20.

53. Jackson RJ, Adnane J, Coppola D, Cantor A, Sebti SM, Pledger WJ. Loss of the cell cycle inhibitors p21(Cip1) and p27(Kip1) enhances tumorigenesis in knockout mouse models. Oncogene. 2002;21(55):8486-97.

54. Vivanco I, Sawyers CL. The phosphatidylinositol 3-Kinase AKT pathway in human cancer. Nat Rev Cancer. 2002;2(7):489-501.

55. Coleman ML, Marshall CJ, Olson MF. RAS and RHO GTPases in G1-rase cell-cycle regulation. Nat Rev Mol Cell Biol. 2004;5(5):355-66.

56. Sears RC, Nevins JR. Signaling networks that link cell prolifera fate. J Biol Chem. 2002;277(14):11617-20. Lu Z, Hunter T. Ubiquitylation and proteasomal degrad? (ion of the p2 p27(Kip1) and p57(Kip2) CDK inhibitors. Cell Cycle. 28n 2):2342-5

58. Roy SK, Srivastava RK, Shankar S. Inhibition of PIJ AKT a MAPK _RK pathways causes activation of FOXO transcri stion factor, le $g$ to cell cycle arrest and apoptosis in pancreatic ca er. J Mol Siqnal. 2010;5:10.

59. Medema RH, Kops GJ, Bos JL, Burgering BM $\mathrm{EX}$-like Fo khead transcription factors mediate cell-cycle regulatio Ras a Nature. 2000;404(6779):782-7.

60. Brunet A, Bonni A, Zigmond U, Lin MZ, O Y Arden KC, Blenis J, Green erg Akt promotes cell survival by phosphorylating and inhlsiting a khead transcription factor. Cell. 1999; 96(6):857-68.

61. Hasson P, Egoz Wink C, Volohonsky G, Jia S, Dinur T, Volk T, Courey AJ, Paroush Z. EGFR ales Groucho-dependent repression to antagonize Notch t. criptional output. Nat Genet. 2005;37(1):101-5.

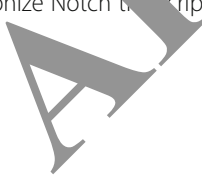

\section{Submit your next manuscript to BioMed Central and we will help you at every step:}

- We accept pre-submission inquiries

- Our selector tool helps you to find the most relevant journal

- We provide round the clock customer support

- Convenient online submission

- Thorough peer review

- Inclusion in PubMed and all major indexing services

- Maximum visibility for your research

Submit your manuscript at www.biomedcentral.com/submit
C) Biomed Central 